Check for updates

Cite this: RSC Adv., 2017, 7, 44743

\title{
Improvement of the amphiphilic properties of a dialkyl phosphate by creation of a protic ionic liquid-like surfactant $\uparrow$
}

\begin{abstract}
Cristian M. O. Lépori, Juana J. Silber, R. Darío Falcone (D)* and N. Mariano Correa
In the present work we have synthesized, via acid-base reaction between bis-(2-ethylhexyl)phosphoric acid (HDEHP) and 1-methylimidazole, a new protic ionic liquid: 1-methylimidazolium bis-(2-ethylhexyl) phosphate (imim-DEHP) with amphiphilic character. The ability of imim-DEHP to create RMs in different nonpolar solvents ( $n$-heptane, benzene and toluene) and spontaneously unilamellar vesicles in water was evaluated by different techniques such as dynamic (DLS) and static (SLS) light scattering and transmission electron microscopy (TEM). The results obtained were compared with the properties of sodium bis-(2ethylhexyl) phosphate (Na-DEHP) in order to elucidate how the surfactant chemical structure affects the organized media generated. Our results show that imim-DEHP forms RMs in aromatic and aliphatic nonpolar solvents and allows the dissolution of a considerable amount of water in both systems. Additionally, imim-DEHP has the capacity to create spontaneously unilamellar vesicles. Interestingly, imim-DEHP shows better characteristics as a surfactant than Na-DEHP. In this sense, we consider that the present work introduces imim-DEHP as a very promising surfactant for future applications as nanoreactors and in nanotechnology.
\end{abstract}

Received 11th August 2017
Accepted 14th September 2017

DOI: $10.1039 / c 7 r a 08907 d$

rsc.li/rsc-advances

solubilized depending on the external solvent, the type of

\section{Introduction}

Ionic liquids (ILs) are a new and more friendly class of compounds which have received significant attention as alternatives to conventional organic solvents. ${ }^{1-3}$ Actually, the great impact that ILs have in chemistry is predominantly due to their properties that can be adapted in the synthesis procedure by a large variety of cation-anion combinations. ${ }^{4,5}$ Depending on the presence or absence of protons (able to interact by $\mathrm{H}$ bonding) in their structures, ILs can be classified as protic or aprotic, respectively. ${ }^{6,7}$ An emerging and attractive field contemplates the synthesis of amphiphilic ILs. ${ }^{8-11}$ These new materials, called IL-like surfactants, have been used to create different kinds of organized systems such as direct micelles, reverse micelles (RMs) and vesicles..$^{3,8,12,13}$

RMs are a kind of organized system, generally described as nanometer sized water droplets dispersed in a nonpolar solvent with the aid of a surfactant monolayer, forming a thermodynamically stable and optically transparent solution. ${ }^{\mathbf{1 4 , 1 5}}$ Different anionic, cationic and nonionic surfactants have been employed to formulate RMs in nonpolar solvents ${ }^{\mathbf{1 4}}$ and, variable amount of water (defined as $W_{0}=[$ water $] /[$ surfactant $]$ ) can be

Departamento de Química, Universidad Nacional de Río Cuarto, Agencia Postal \# 3, C.P. X5804BYA Río Cuarto, Argentina.E-mail: rfalcone@exa.unrc.edu.ar

$\dagger$ Electronic supplementary information (ESI) available: NMR and FT-IR characterization of imim-DEHP, experimental detailed procedures and DLS data, are available free of charge. See DOI: 10.1039/c7ra08907d surfactant and temperature. ${ }^{\mathbf{1 4 - 1 6}}$

On the other hand, the use of protic ILs to prepare RMs is

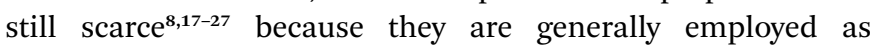
a replacement for water as the polar phase in direct micelles or vesicles. $^{28}$

The comparison between the behavior of bulk and confined water inside RMs has been inspiration of numerous investigations. Thus, studies about polarity, viscosity, conductivity and $\mathrm{H}$-bonding for water entrapped in RMs have been performed and compared with bulk solution. ${ }^{15,29-38}$ These investigations showed that as a result of the specific interactions but mainly due to confinement, the physicochemical properties of water entrapped inside RMs change dramatically from the bulk. ${ }^{35}$ Particularly, it was demonstrated that the magnitude of the alterations on the water structure are strongly dependent on the kind of surfactant used to form the organized system. ${ }^{30,39,40}$ Previous studies performed in our group have shown very peculiar and interesting water properties inside RMs that emerges from the confinement effect and the interaction with the surfactant at the interface..$^{\mathbf{3 0 , 3 1 , 3 9 , 4 1}}$ In this sense, if anionic or cationic surfactants are used to prepare the RMs, the water properties differ significantly among each other. For example, water molecules entrapped inside RMs formed by sodium 1,4bis-2-ethylhexylsulfosuccinate (Na-AOT), show enhanced electron donor ability compared with bulk water, while water entrapped inside benzyl- $n$-hexadecyldimethylammonium chloride (BHDC) RMs appears as non electron-donating due to its 
interaction with the cationic surfactant polar headgroup. ${ }^{\mathbf{3 0 4} \mathbf{4 1}}$ These results have tremendous impact on the applications of these supramolecular assemblies, for example when they are used as nanoreactors. ${ }^{\mathbf{4 1 - 4 4}}$

Vesicles are spherical aggregates formed in water by some amphiphilic compounds (commonly phospholipids), where the lipid bilayer surrounds an aqueous core. ${ }^{45}$ To prepare large unilamellar vesicles (LUVs) it is mandatory the use of different techniques (such as ultra-sonication or extrusion) to convert multilamellar vesicles (formed spontaneously) into LUVs. ${ }^{45,46}$ These vesicles can enhance drug stability, therapeutic effects, and uptake of the solubilized drug into the target site with reduced toxicity. ${ }^{45}$ However, its stability under extreme conditions is still a challenge and consequently the design of new surfactants is an interesting area to investigate.

Dialkyl phosphates and their alkaline salts are of interest in extraction processes because of their complexing properties toward metal ions and for this reason are relevant in areas such as hydrometallurgy, nuclear industry and biological materials. ${ }^{\mathbf{1 8 , 4 7 - 5 9}}$ Particularly, the sodium bis-(2-ethylhexyl)phosphate (Na-DEHP) surfactant has the capacity to generate organized media such as RMs in nonpolar organic solvents as first pointed out by Eicke and Christen. ${ }^{\mathbf{6 0}, 61}$ Initially, Na-DEHP was investigated for two main reasons: (i) similar nonpolar region to the widely used anionic surfactant Na-AOT and, (ii) phosphate headgroup similar to phospholipids.

Interestingly, an unusual behavior of Na-DEHP depending on the kind of nonpolar (aromatic or aliphatic) solvents used has been reported. Thus, benzene/Na-DEHP/water system have been explored by ${ }^{1} \mathrm{H}$ NMR, densimetry, light and neutron scattering techniques. ${ }^{62}$ The experiments showed that the stability of the RMs is observed at $W_{0}<6$ and a minimal of water content of $0.75-1$ to form the system is required. Also, Faure et al. determined a mean aggregation number $\left(N_{\text {agg }}\right)$ of $12 \pm 1$ and a critical micellar concentration $(\mathrm{cmc})$ of $8 \times 10^{-3} \mathrm{M}$ to the system at $W_{0}=4 .^{62,63}$

In aliphatic solvents such as $n$-heptane, Na-DEHP behavior is still more confusing. Neuman et al. ${ }^{64}$ studied the micellization process of Na-DEHP in $n$-heptane using dynamic (DLS) and static (SLS) light scattering techniques. The results showed that traces of water have a very dramatic effect on the RMs formation. In contrast with results in the literature for other RMs, the water presence in $n$-heptane/Na-DEHP system seemed to act as an antimicellization agent. Later studies from the same group showed that Na-DEHP in $n$-heptane forms giant rodlike RMs, ${ }^{64-66}$ with a radius of gyration of $53 \mathrm{~nm}$, which contrasted with the literature view, at that time, that the $N_{\mathrm{agg}}$ in nonpolar media are much smaller (rarely exceeding 20) than those in aqueous media.

On the other hand, an alternative explanation for the results reported by Neuman et $a .^{64-66}$ and the water antimicellization idea was proposed and challenged by Feng and Schelly. ${ }^{67,68}$ In this sense, several properties of benzene/Na-DEHP/water system were studied and the results suggested the existence of a critical water content value $\left(W_{0} \sim 3\right)$; below this value the aggregates are large rod-shaped dipolar crystallites with the same structure as the constituent rods of the hexagonal liquid crystalline solid state of Na-DEHP. At $W_{0}>3$, the large aggregates successively dissolve

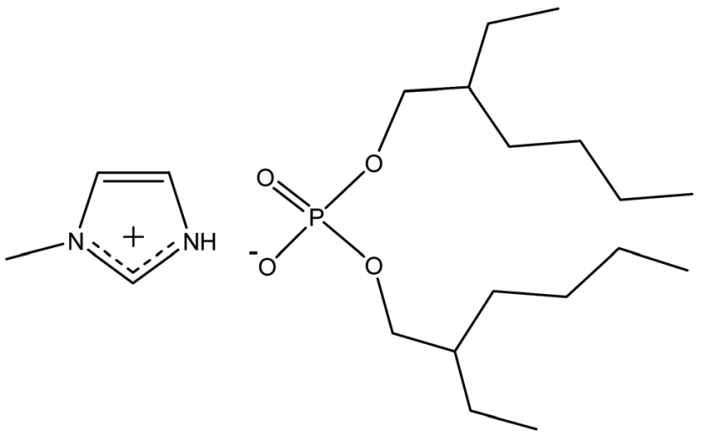

imim-DEHP

Scheme 1 Molecular structure of the surfactant imim-DEHP.

and become into spherical RMs which sizes increase with the $W_{0}$ value. Also they have shown that the benzene/Na-DEHP/water RMs sizes are larger than the benzene/Na-AOT/water RMs.

Quintana et $a .^{39}$ studied the micropolarity and microviscosity of the water/surfactant interface, interfacial water structure, molecular probes partition and intramolecular electron transfer processes of aqueous Na-DEHP and Na-AOT RMs in toluene. The results revealed that because of the different water-surfactant interactions, those properties are substantially dissimilar in both RMs.

More recently, ${ }^{69}$ the behavior of two polar solvents: ethylene glycol (EG) and dimethylformamide (DMF), entrapped in $n$-heptane/Na-DEHP RMs were investigated using DLS, UV-visible and FT-IR spectroscopies. The formation of RMs containing EG and DMF as a polar component was confirmed by DLS. By molecular probe solvatochromism and FT-IR, it was demonstrated that Na-DEHP interacts through hydrogen bond with EG at the EG/Na-DEHP interface and this interaction destroy the bulk structure of pure EG when entrapped in Na-DEHP RMs. On the other hand, when DMF is incorporated inside the RMs the bulk structure of DMF is destroyed upon encapsulation by the Na-DMF interaction at the DMF/Na-DEHP interface.

Taking into account that the dialkyl phosphates surfactants represent an interesting field to explore, in the present work we have synthesized a new protic IL with amphiphilic character by the acid-base reaction between bis-(2-ethylhexyl)phosphoric acid (HDEHP) and 1-methylimidazole, forming 1-methylimidazolium bis-(2-ethylhexyl)phosphate (imim-DEHP, Scheme 1). By DLS and SLS techniques the ability of imim-DEHP to create RMs in different nonpolar solvents ( $n$-heptane, benzene and toluene) was evaluated. The results obtained were compared with Na-DEHP in order to elucidate if the surfactant chemical structure affects the organized media generated. Additionally, imim-DEHP was tested in water in order to explore its capacity to form vesicles; in this case DLS and TEM were employed.

\section{Experimental section}

\section{Materials}

Bis-(2-ethylhexyl)phosphoric acid (HDEHP) from Fluka (>95\% purity) was used as received. 1-Methylimidazole from Sigma 
Aldrich ( $>99 \%$ purity) was distilled under vacuum before using. Ultrapure water was obtained from Labonco equipment model 90901-01. Benzene, $n$-heptane, $\mathrm{CDCl}_{3}$ and toluene, all from Sigma Aldrich (HPLC quality) were used without prior purification.

imim-DEHP preparation. The protic IL-like surfactant used, 1-methylimidazolium bis-(2-ethylhexyl)phosphate (imimDEHP), which is a colorless and highly viscous liquid (mp < $-18{ }^{\circ} \mathrm{C}$ ) was formed under inert conditions by mixing equimolar quantities of the base (1-methylimidazole) and the acid (HDEHP) as is descripted in ESI section. $\dagger$ Additionally, in Table S1 and Fig. S1-S3† are shown the ${ }^{1} \mathrm{H},{ }^{31} \mathrm{P}$ NMR and FT-IR data of imim-DEHP characterization.

Prior to use, imim-DEHP was dried under vacuum for 4 hours.

\section{Methods}

Detailed experimental procedure of the imim-DEHP RMs and vesicles preparation; DLS, SLS and TEM experiments are shown in the ESI section. $\dagger$

\section{Results and discussion}

To evaluate if the IL imim-DEHP can be used as surfactant to generate RMs, initially the phase diagram of the ternary system: nonpolar solvent/surfactant/water was investigated. Thus, the imim-DEHP solubility in different nonpolar solvents, such as benzene, toluene and $n$-heptane, was tested. It was observed that imim-DEHP is soluble at least until $0.2 \mathrm{M}$ in all solvents in absence of water. Furthermore, the amount of water that can be dispersed in the nonpolar solvent/imim-DEHP solutions forming clear and stable ternary mixtures is summarized in Table 1, for $[$ imim-DEHP] $=0.2 \mathrm{M}$. The maximum amount of water solubilized in the different imim-DEHP systems is defined as $W_{0}^{\max }$. For comparison, in Table 1 are also included the NaDEHP systems prepared in the nonpolar solvents evaluated.

As it can be observed, the $W_{0}^{\max }$ values reached for the aromatic solvents/imim-DEHP systems are quite similar but smaller than for $n$-heptane. Interestingly, both aromatic and aliphatic systems are able to dissolve substantially more water than the corresponding system using Na-DEHP as surfactant. These results suggest that the presence of a protic cationic counterion, which can interact by electrostatic and hydrogen

Table 1 Maximum amount of water solubilized $\left(W_{0}^{\max }\right)$ in different systems at [surfactant] $=0.2 \mathrm{M} . T=25^{\circ} \mathrm{C}$

\begin{tabular}{lll}
\hline & $W_{0}^{\max }$ & \\
\cline { 2 - 3 } Nonpolar solvent & imim-DEHP & Na-DEHP \\
\hline$n$-Heptane & $39 \pm 1$ & $20-25^{a}$ \\
Benzene & $15 \pm 1$ & $5-6^{b}$ \\
Toluene & $16 \pm 1$ & $10 \pm 1^{c}$
\end{tabular}

${ }^{a}$ Values obtained from ref. 70 and $71 .{ }^{b}$ Values obtained from ref. 62, 67 and $72 .^{c}$ Value obtained from ref. 39. bond interactions with the microenvironment, change significantly the surfactant behavior. Thus, it is interesting to investigate if this structural difference $\left(\mathrm{imim}^{+}\right.$and $\mathrm{Na}^{+}$) produces other modifications such as droplets sizes, water-interface interactions, among others.

To evaluate the formation of RMs, the systems formed by toluene/imim-DEHP/water and $n$-heptane/imim-DEHP/water were studied by DLS technique. When new RMs are discovered, it is imperative to demonstrate that water molecules are effectively entrapped by the surfactant monolayer creating true RMs. $^{73-75}$ If this does not occur, the water molecules would be only dissolved in the organic solvent/surfactant mixture without any molecular organization forming a structureless microemulsion. $^{74}$ Both systems (RMs and structureless microemulsion) show notable differences in the physicochemical properties of the water dissolved. ${ }^{74}$ Thus, if water is really encapsulated and interacts with the RM interface, the droplets size must increase as the $W_{0}$ value increases with a linear tendency (swelling law of RMs) as it is well established for other $\mathrm{RMs}^{76}$ Deviations from the linearity on the droplets sizes indicates that the RMs micelle-micelle interactions are favored, producing a change over the shape of the RMs previous to the phase separation. ${ }^{\mathbf{4 3 , 7 6 - 7 9}}$ In contrast, if water is not encapsulated by the surfactant monolayer, the diameter of the aggregates should remain constants or even decrease with the polar solvent addition. ${ }^{74}$

In the present work, all the DLS experiments were made at surfactant concentration equal to $0.1 \mathrm{M}$ and even though the RMs solutions are not at infinite dilution an apparent hydrodynamic diameter $\left(d_{\mathrm{app}}\right)$ can be defined. ${ }^{\mathbf{8 0}, \mathbf{8 1}}$ In Fig. 1, are depicted the $d_{\text {app }}$ values for the imim-DEHP/nonpolar solvents solutions studied at different $W_{0}$ values. Moreover, in Table S2 in the ESI section $\uparrow$ the polydispersity index (PDI) values obtained are reported. Similar behavior of imim-DEHP was

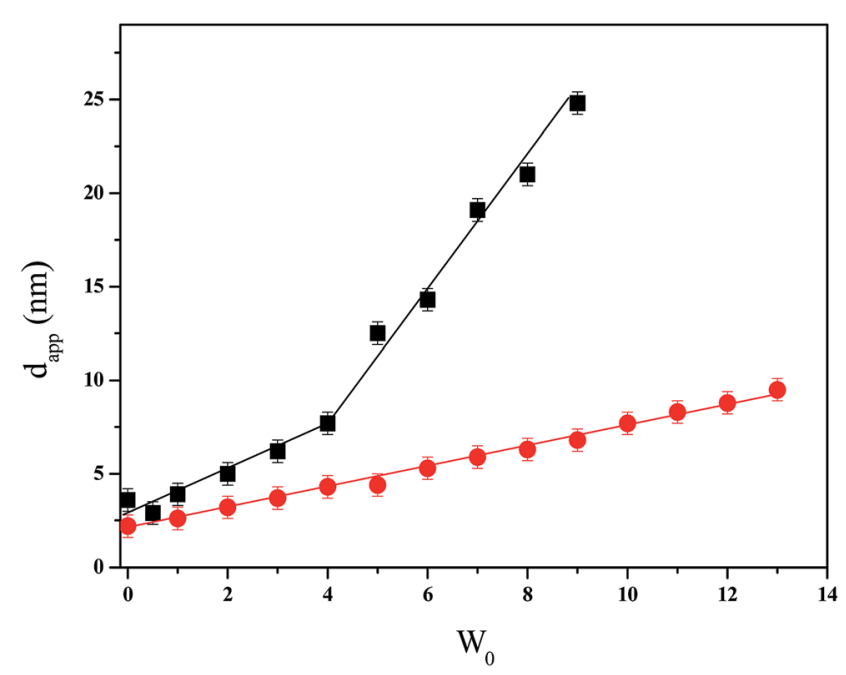

Fig. 1 Apparent diameter $\left(d_{\mathrm{app}}\right)$ values of the $(\boldsymbol{\square}) n$-heptane/imimDEHP/water RMs and ( $\bullet$ toluene/imim-DEHP/water RMs obtained at $25{ }^{\circ} \mathrm{C}$ varying $W_{0}$. The straight line is plotted to guide the eye limim$\mathrm{DEHP}]=0.1 \mathrm{M}$. 
observed when dissolved in toluene or benzene (see $d_{\text {app }}$ values in Fig. S4 in ESI section $\dagger$ ).

From Fig. 1 and Table S2 $\uparrow$ several facts can be observed: (i) the increase in the droplet size values in both systems when the water content increases; (ii) different profiles of the plots when the water is entrapped by imim-DEHP/toluene or imim-DEHP/ $n$-heptane solutions; (iii) at similar water content, imim-DEHP RMs in $n$-heptane are larger than in toluene; and (iv) the low PDI values obtained (0.02-0.1) for the majority of the systems when water is present.

The existence of organized media is proven, since as observed in Fig. 1 water is entrapped by the imim-DEHP surfactant layer yielding RMs..$^{32,74,82,83}$ However, the $d_{\text {app }}$ values are strongly dependent on the nonpolar solvent used and the amount of water entrapped. Thus, a gradual linear increment is observed for the RMs formed in toluene, while a clear break is observed in $n$-heptane. Particularly, the abrupt increment in the droplets sizes observed in $n$-heptane at $W_{0}>4$ could be interpreted as a shape change of the aggregate probably due to a dramatic increase in the droplet-droplet interaction. ${ }^{69,84}$ Thus, at $W_{0}<4$ the RMs are probably spherical (as in toluene) but at larger water content a rod-like or ellipsoidal system could be formed. ${ }^{69,84}$ The low PDI values observed for both imim-DEHP RMs suggest that the particles are essentially monodisperse. ${ }^{85}$

With regard to the imim-DEHP dependence on the water content, it is interesting to remark that in both nonpolar solvents it is possible to determine the droplets size values at $W_{0}=0$, fact that is not possible for Na-DEHP. Thus, in imimDEHP/toluene media it can be detected organized media in absence of water addition while in Na-DEHP/benzene the lowest $W_{0}$ content reported is $0.75-1 .^{67}$ Additionally, Neuman et al. ${ }^{65,66}$ describe that water in Na-DEHP/ $n$-heptane RMs act as antimicellization agent, fact that is completely different for imimDEHP RMs. Thus, the presence of a protic cation in the surfactant structure helps the aggregation process even in absence of water. Probably, the existence of a hydrogen atom in the cationic component of the surfactant able to interact by $\mathrm{H}$-bonding, reinforces the interaction with the anionic moiety $\left(\mathrm{DEHP}^{-}\right)$at $W_{0}=0$ and promotes the RMs formation.

At similar $W_{0}$ the droplets sizes of the imim-DEHP $/ n$-heptane RMs are larger than in toluene. In this sense, when RMs sizes are analyzed is interesting to think what happen with an important factor in this kind of supramolecular assemblies: the effective packing parameter of the surfactant, $p$. This parameter

Table 2 Aggregation numbers $\left(N_{\text {agg }}\right)$ and apparent hydrodynamic diameter $\left(d_{\mathrm{app}}\right)$ for the toluene/imim-DEHP/water and $n$-heptane/ imim-DEHP/water RMs at different $W_{0} . T=25^{\circ} \mathrm{C}$

\begin{tabular}{|c|c|c|c|c|}
\hline \multirow[b]{2}{*}{$W_{0}$} & \multicolumn{2}{|c|}{$\begin{array}{l}\text { Toluene/imim-DEHP/ } \\
\text { water }\end{array}$} & \multicolumn{2}{|c|}{$\begin{array}{l}n \text {-Heptane/imim-DEHP/ } \\
\text { water }\end{array}$} \\
\hline & $d_{\mathrm{app}}{ }^{a}(\mathrm{~nm})$ & $N_{\text {agg }}$ & $d_{\mathrm{app}}{ }^{a}(\mathrm{~nm})$ & $N_{\text {agg }}$ \\
\hline 0 & $2.2 \pm 0.5$ & $15 \pm 2$ & $3.6 \pm 0.3$ & $25 \pm 2$ \\
\hline 4 & $4.3 \pm 0.1$ & $35 \pm 3$ & $7.7 \pm 0.1$ & $83 \pm 4$ \\
\hline 8 & $6.3 \pm 0.1$ & $72 \pm 5$ & $21.0 \pm 0.1$ & $394 \pm 15$ \\
\hline
\end{tabular}

is defined as $p=v / a l_{\mathrm{c}}$, where $v$ and $l_{\mathrm{c}}$ are the volume and the length of the hydrocarbon chain, respectively and $a$ is the surfactant head group area. ${ }^{85}$ The diameters of the RMs are larger when the $p$ values are smaller. ${ }^{86,87}$ Consequently, all the features that decrease the $v$ values and/or increase the $a$ values decrease the $p$ values affecting the sizes of the RMs. Thus, our results (imim-DEHP/n-heptane vs. imim-DEHP/toluene RMs) can be explained considering different nonpolar solvent penetration to the interface. It is well known that in other RMs such as in Na-AOT and BHDC RMs, the aromatic solvents are able to penetrate deeper the interface than aliphatic solvents. ${ }^{43,44,73}$ This particular solvent penetration modifies the surfactant packing parameter and consequently the RMs sizes. For example, for Na-AOT RMs benzene molecules penetrate easily to the interfacial zone in comparison to $n$-heptane. As a result, at the same $W_{0}$ value the Na-AOT/benzene RMs are smaller than the AOT $/ n$-heptane RMs. ${ }^{43}$ Moreover, we have previously demonstrated that the type or composition of the nonpolar phase also alter the micelle-micelle interactions and the water structure inside the RMs. ${ }^{43,44,73,78,79,88}$ Thus, we found that when aromatic solvents are used, the intermicellar interactions decrease while when aliphatic solvents are employed these interactions increase. This fact has remarkable impact on the practical application of RMs as nanoreactors, ${ }^{43,44}$ for example in the nanoparticle synthesis where one of the key steps that controls the synthetic pathway is the coalescence process, which is regulated by intermicellar interactions. ${ }^{89}$ Thus, in our case $n$ heptane favors the intermicellar interactions and the shape transition, as it is observed from Fig. 1.

It is interesting to note that the $d_{\text {app }}$ values for imim-DEHP are quite different to the reported by Na-DEHP in the same nonpolar solvents. ${ }^{65,67}$ For example, imim-DEHP/toluene show a $d_{\text {app }}$ equal to $2.6 \mathrm{~nm}$ at $W_{0}=1$, being the droplets size $18.3 \mathrm{~nm}$ in Na-DEHP/benzene. ${ }^{67}$ In $n$-heptane, the differences are even larger, for example Na-DEHP shows a size of $33.8 \mathrm{~nm}$ at $W_{0}=$ $3.2,{ }^{65,66}$ however imim-DEHP at similar water content has a diameter of $6.2 \mathrm{~nm}$. If we consider that the volume $v$ and $l_{\mathrm{c}}$ are similar between imim-DEHP and Na-DEHP, the replacement of $\mathrm{Na}^{+}$by the larger imidazolium cation produces an increase in the area $a$. Additionally, the protic $\mathrm{imim}^{+}$can interact by H-bonding with the water molecules and with the anion DEHP, also modifying $a$. Both facts reduce the $p$ value and it would be expected an increase on the droplets sizes, however the imimDEHP RMs are smaller than the Na-DEHP. Thus, the main reason for these differences is that as it was mentioned before, Na-DEHP does not form spherical aggregates in both solvents, especially when the water content increases. ${ }^{17,65}$ In this sense, the shapes of the systems created by both surfactants are not comparable.

In order to support the idea that the replacement of $\mathrm{Na}^{+}$by $\mathrm{imim}^{+}$produces dramatic alteration at the interfacial level in the RMs formed than the DLS results could explain, SLS technique was used. Thus, $N_{\text {agg }}$ of imim-DEHP in toluene and $n$-heptane at different $W_{0}$ were determined and, the values are listed in Table 2. The methodology employed to estimate the $N_{\text {agg }}$ values is according to literature. ${ }^{90-92}$ Hence, SLS technique was used to determine the micellar molecular weights $\left(M_{\mathrm{w}}\right)$ at 
different surfactant concentrations at fixed $W_{0}$, by means of the well-known Rayleigh expression. ${ }^{92}$ Thus, for every RMs and $W_{0}$ explored, the $M_{\mathrm{w}}$ and consequently $N_{\text {agg }}$ values were determined (see methodology descripted in the ESI $\dagger$ ).

As it can be seen from Table 2, as the water content increase the $N_{\text {agg }}$ values increase in both RMs; however different magnitudes are observed between the imim-DEHP/toluene and imim-DEHP $/ n$-heptane RMs. For example, at $W_{0}=8$ in imimDEHP $/ n$-heptane the $N_{\text {agg }}$ is 394 in comparison with 72 for imim-DEHP/toluene. These differences, especially at larger $W_{0}$, reinforce the idea that shape transition from spherical to ellipsoidal or rod-like in $n$-heptane, as it was invoked from the DLS data, could be possible. Additionally, these $N_{\text {agg }}$ values agree with a stronger intermicellar interaction in $n$-heptane than in toluene.

Taking into account all the results showed, the interfacial region in both RMs is quite different. In imim-DEHP/toluene RMs, the aromatic solvent penetrates more the interface and expels the water molecules and the $\mathrm{imim}^{+}$counterions to the water pool. On the other hands, in imim-DEHP/n-heptane RMs
Table 3 Apparent hydrodynamic diameter $\left(d_{\mathrm{app}}\right)$ and polydispersity index (PDI) values of imim-DEHP vesicles in water at different surfactant concentrations. $T=25^{\circ} \mathrm{C}$

\begin{tabular}{llll}
\hline $\begin{array}{l}\text { Surfactant concentration } \\
\left(10^{-4} \mathrm{M}\right)\end{array}$ & $d_{\text {app }}(\mathrm{nm})$ & PDI & $\begin{array}{l}\text { Zeta potential } \\
(\mathrm{mV})\end{array}$ \\
\hline 0.2 & $120 \pm 5$ & 0.3 & $-46 \pm 2$ \\
1.0 & $139 \pm 5$ & 0.3 & $-55 \pm 2$ \\
3.0 & $146 \pm 5$ & 0.1 & $-45 \pm 2$ \\
5.0 & $121 \pm 5$ & 0.2 & $-47 \pm 2$ \\
7.0 & $122 \pm 5$ & 0.1 & $-50 \pm 2$
\end{tabular}

the nonpolar solvent does not penetrate the interface and the imim $^{+}$is inserted between the anionic components of the surfactant. Additionally, the water molecules can interact strongly with both components of the surfactant at the interface. Similar penetration phenomena were observed in RMs formed by BHDC and Na-AOT. ${ }^{\mathbf{4 4 , 7 3 , 7 8 , 8 8}}$ In Scheme 2 are plotted a probable schematic representation of both novel RMs.

\section{A}



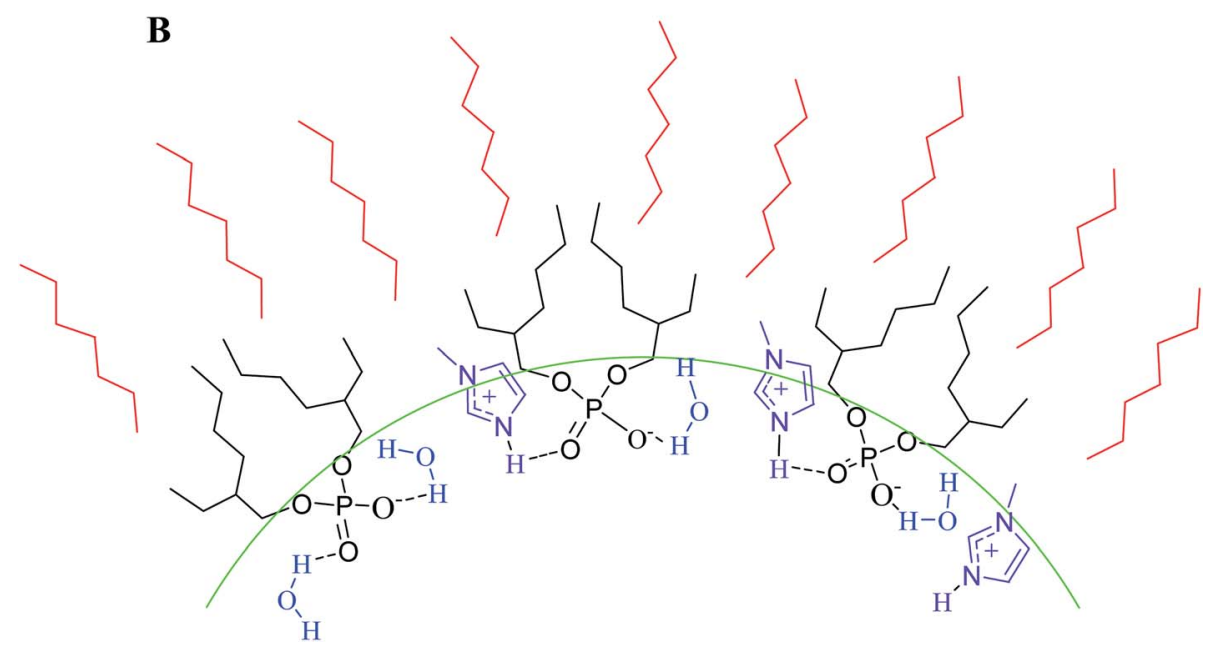

Scheme 2 Schematic representation of imim-DEHP surfactant and water molecules location at the interface in the non-polar solvent/imim$\mathrm{DEHP} /$ water RMs (A) toluene and (B) $n$-heptane. 




Fig. 2 TEM image (negatively stained 2\% phosphotungstic acid) of imim-DEHP vesicles [imim-DEHP] $=3 \times 10^{-4} \mathrm{M}$. Scale bar $=0.5 \mu \mathrm{m}$.

In order to extend the knowledge of the imim-DEHP capacity as surfactant, its behavior in pure water was also investigated. Thus, different solutions of imim-DEHP in water were prepared and the aqueous opalescent samples without any other procedure to prepare them were analyzed by DLS. Table 3 show the $d_{\text {app }}$ values obtained for imim-DEHP in water at $25{ }^{\circ} \mathrm{C}$. As it observed, the DLS data denote the formation of aggregates with diameters ranging from 120-140 $\mathrm{nm}$ with low polydispersity index (0.1-0.3) values. Moreover, in the range of $2 \times 10^{-5} \mathrm{M}$ to $7 \times 10^{-4} \mathrm{M}$ the sizes were independent on the imim-DEHP concentration.

From Table 3, two facts can be highlighted: (i) the detection of aggregates in the whole concentration range explored even in diluted systems and; (ii) the independency on the diameter values measured at different [imim-DEHP]. Both evidences are suggesting that an organized media is created (spontaneously), which could be vesicles or direct micelles. ${ }^{46}$ Taking into account that the surfactant concentrations range explored is broad, including values around $10^{-5} \mathrm{M}$ which are smaller to the cmc for micelles created by traditional anionic surfactants in water, ${ }^{93}$ we consider that the aggregate observed are vesicles and not direct micelles. The observation of aggregates even at $10^{-5} \mathrm{M}$ and considering that the sizes of direct micelles are generally only of a few $\mathrm{nm},{ }^{\mathbf{9 4 - 9 6}}$ contrary to the values reported in Table 2, support the vesicles formation. Moreover, the aggregates obtained at different [imim-DEHP] concentrations present low polydispersity index, suggesting that they are unilamellar vesicles. $^{12}$

Zeta potential is an important parameter to determine the stability of vesicles and its interaction with biological system. ${ }^{\mathbf{9}}$ Zeta potential values were determined in all the samples as are depicted in Table 3. The results obtained show vesicles with zeta potential values around $-46 \mathrm{mV}$ at the different surfactant concentration explored, suggesting that anionic moieties are exposed to the outer face of the vesicle bilayer.

In order to further characterize the organized system obtained, transmission electron microscopy (TEM) micrograph of vesicles of imim-DEHP was performed as shown in Fig. 2. As can be observed the diameters and homogeneous distribution are comparable to those measured for the aggregates by DLS.

These facts are very interesting due to neither HDEHP (Scheme S1 $\dagger$ ) nor Na-DEHP have the ability to form vesicles in water, denoting that the chemical structure of cationic component in the new surfactant impact strongly in its aggregation process. ${ }^{98}$ In this sense, some geometrical considerations about the packing parameter, $p$, can be invoked. It is wellknown that the formation of vesicles is favored to occur in systems with $p$ between $1 / 2$ and $1 .{ }^{99}$ Taking into account that the length of the hydrocarbon chain $l_{\mathrm{c}}$ and probably the $a$ values (considering only the amphiphilic moiety $\mathrm{DEHP}^{-}$) in the surfactants HDEHP, Na-DEHP and imim-DEHP are quite similar; the main difference could be in the value of $v$. We hypothesize that the replacement of the $\mathrm{Na}^{+}$(or $\mathrm{H}$ ) counterion on DEHP by the more hydrophobic and large $\mathrm{imim}^{+}$generates an increment in the hydrophobic volume of the surfactant. ${ }^{\mathbf{1 0 0 , 1 0 1}}$ This idea is supported by the zeta potential value $(-46 \mathrm{mV})$ found in our system, that is suggesting that $\mathrm{imim}^{+}$is located deep in the bilayer. This particular location produces a $p$ larger than in HDEPH or Na-DEHP, which is more appropriated to form vesicles.

\section{Conclusions}

In summary, we believe that the results showed in the present work make imim-DEHP as a very promissory surfactant. This versatile new amphiphilic IL can be formed easily by acid-base reaction and it allows to create RMs in aromatic and aliphatic nonpolar solvents with very different interfacial properties. Additionally, imim-DEHP has the capacity to create spontaneously unilamellar vesicles. Interestingly, imim-DEHP show better characteristics as surfactant than Na-DEHP. In this sense, we are now exploring more properties such as micropolarity, microviscosity, and electron and hydrogen bond donor abilities, in order to improve its potential for future applications in nanotechnology as nanoreactors (RMs) and as drug delivery systems (vesicles).

\section{Conflicts of interest}

The authors declare no competing financial interests.

\section{Acknowledgements}

Financial support from Consejo Nacional de Investigaciones Científicas y Técnicas (CONICET, PIP CONICET 112-20110100204), Universidad Nacional de Río Cuarto, Agencia Nacional de Promoción Científica y Técnica (PICT 2012-0232, PICT 20120526 and PICT 2015-0585), and Ministerio de Industria, Comercio, Minería y Desarrollo Científico Tecnológico de Córdoba (PID-2013) is gratefully acknowledged. J. J. S., N. M. C. and R. D. 
F. hold a research position at CONICET. C. M. O. L. thanks CONICET for a research fellowship.

\section{References}

1 J. P. Hallett and T. Welton, Chem. Rev., 2011, 111, 35083576.

2 P. Wasserscheid and T. Welton, Ionic Liquids in Synthesis: Second Edition, Wiley-VCH Verlag GmbH \& Co. KGaA, Weinheim, Germany, 2008, vol. 1.

3 R. D. Falcone, N. M. Correa, J. J. Silber and N. E. Levinger, in Ionic Liquid-Based Surfactant Science, John Wiley \& Sons, Inc, Hoboken, NJ, 2015, pp. 283-301.

4 T. Welton, Chem. Rev., 1999, 99, 2071-2083.

5 S. K. Das, D. Majhi, P. K. Sahu and M. Sarkar, ChemPhysChem, 2017, 18, 198-207.

6 C. A. Angell, N. Byrne and J. P. Belieres, Acc. Chem. Res., 2007, 40, 1228-1236.

7 C. Austen Angell, Y. Ansari and Z. Zhao, Faraday Discuss., 2012, 154, 9-27.

8 B. K. Paul and S. P. Moulik, Ionic Liquid-Based Surfactant Science, John Wiley \& Sons, Inc, Hoboken, NJ, 2015.

9 D. Majhi, A. Pabbathi and M. Sarkar, J. Phys. Chem. B, 2016, 120, 193-205.

10 S. K. Das, D. Majhi, P. K. Sahu and M. Sarkar, $R S C A d v$, 2015, 5, 41585-41594.

11 D. Majhi, P. K. Sahu, S. Seth and M. Sarkar, Phys. Chem. Chem. Phys., 2016, 18, 22343-22354.

12 C. C. Villa, F. Moyano, M. Ceolin, J. J. Silber, R. D. Falcone and N. M. Correa, Chem.-Eur. J., 2012, 18, 15598-15601.

13 C. C. Villa, N. M. Correa, J. J. Silber, F. Moyano and R. D. Falcone, Phys. Chem. Chem. Phys., 2015, 17, 1711217121.

14 N. M. Correa, J. J. Silber, R. E. Riter and N. E. Levinger, Chem. Rev., 2012, 112, 4569-4602.

15 J. J. Silber, A. Biasutti, E. Abuin and E. Lissi, Adv. Colloid Interface Sci., 1999, 82, 189-252.

16 T. K. De and A. Maitra, Adv. Colloid Interface Sci., 1995, 59, 95-193.

17 L. García-Río, P. Hervella and P. Rodríguez-Dafonte, Langmuir, 2006, 22, 7499-7506.

18 G. D. Rees, R. Evans-Gowing, S. J. Hammond and B. H. Robinson, Langmuir, 1999, 15, 1993-2002.

19 D. C. Steytler, D. L. Sargeant, G. E. Welsh, B. H. Robinson and R. K. Heenan, Langmuir, 1996, 12, 5312-5318.

20 J. C. Thater, V. Gérard and C. Stubenrauch, Langmuir, 2014, 30, 8283-8289.

21 L. Liu and J. Hao, Tenside, Surfactants, Deterg., 2017, 54, 214-219.

22 M. Moniruzzaman, N. Kamiya and M. Goto, Langmuir, 2009, 25, 977-982.

23 O. Zech and W. Kunz, Soft Matter, 2011, 7, 5507-5513.

24 Q. Li, X. Wang, X. Yue and X. Chen, Langmuir, 2014, 30, 1522-1530.

25 C. Dai, S. Wang, M. Du, Y. Liu, D. Peng, Z. Yan and M. Zhao, Colloid Polym. Sci., 2015, 293, 1475-1481.
26 O. Zech, S. Thomaier, P. Bauduin, T. Ruck, D. Touraud and W. Kunz, J. Phys. Chem. B, 2009, 113, 465-473.

27 S. K. Mehta and K. Kaur, Indian J. Chem., Sect. A: Inorg., Bioinorg., Phys., Theor. Anal. Chem., 2010, 49, 662-684.

28 T. L. Greaves and C. J. Drummond, Chem. Rev., 2015, 115, 11379-11448.

29 N. M. Correa, M. A. Biasutti and J. J. Silber, J. Colloid Interface Sci., 1996, 184, 570-578.

30 D. Blach, N. M. Correa, J. J. Silber and R. D. Falcone, J. Colloid Interface Sci., 2011, 355, 124-130.

31 S. S. Quintana, F. Moyano, R. D. Falcone, J. J. Silber and N. M. Correa, J. Phys. Chem. B, 2009, 113, 6718-6724.

32 E. Odella, R. D. Falcone, J. J. Silber and N. M. Correa, Phys. Chem. Chem. Phys., 2014, 16, 15457-15468.

33 M. A. Crosio, J. J. Silber, R. D. Falcone and N. M. Correa, Dyes Pigm., 2017, 138, 68-76.

34 T. L. Spehr, B. Frick, M. Zamponi and B. Stühn, Soft Matter, 2011, 7, 5745-5755.

35 N. M. Correa and N. E. Levinger, J. Phys. Chem. B, 2006, 110, 13050-13061.

36 R. E. Riter, D. M. Willard and N. E. Levinger, J. Phys. Chem. B, 1998, 102, 2705-2714.

37 B. Baruah, J. M. Roden, M. Sedgwick, N. M. Correa, D. C. Crans and N. E. Levinger, J. Am. Chem. Soc., 2006, 128, 12758-12765.

38 I. R. Piletic, D. E. Moilanen, D. B. Spry, N. E. Levinger and M. D. Fayer, J. Phys. Chem. A, 2006, 110, 4985-4999.

39 S. S. Quintana, R. D. Falcone, J. J. Silber and N. M. Correa, ChemPhysChem, 2012, 13, 115-123.

40 F. Moyano, S. S. Quintana, R. D. Falcone, J. J. Silber and N. M. Correa, J. Phys. Chem. B, 2009, 113, 4284-4292.

41 F. Moyano, R. D. Falcone, J. C. Mejuto, J. J. Silber and N. M. Correa, Chem.-Eur. J., 2010, 16, 8887-8893.

42 N. M. Correa, E. N. Durantini and J. J. Silber, J. Org. Chem., 1999, 64, 5757-5763.

43 J. A. Gutierrez, R. D. Falcone, M. A. Lopez-Quintela, D. Buceta, J. J. Silber and N. M. Correa, Eur. J. Inorg. Chem., 2014, 2095-2102.

44 J. A. Gutierrez, M. A. Luna, N. M. Correa, J. J. Silber and R. D. Falcone, New J. Chem., 2015, 39, 8887-8895.

45 B. S. Pattni, V. V. Chupin and V. P. Torchilin, Chem. Rev., 2015, 115, 10938-10966.

46 R. R. C. New, Liposomes: a practical approach, IRL Press, New York, 1990.

47 C. Shi, Y. Jing, J. Xiao, X. Wang, Y. Yao and Y. Jia, Sep. Purif. Technol., 2017, 172, 473-479.

48 L. Zhu, Q. Zhao, X. Wu, G. Zhao and X. Wang, Tribol. Int., 2016, 97, 192-199.

49 K. Ooi, Y. Tasaki-Handa, Y. Abe and A. Wakisaka, Dalton Trans., 2014, 43, 4807-4812.

50 A. Rout, J. Kotlarska, W. Dehaen and K. Binnemans, Phys. Chem. Chem. Phys., 2013, 15, 16533-16541.

51 Z.-J. Yu, T. H. Ibrahim and R. D. Neuman, Solvent Extr. Ion Exch., 1998, 16, 1437-1463.

52 V. Sharma, N. Doerr and P. B. Aswath, RSC Adv., 2016, 6, 22341-22356. 
53 A. Rout, K. A. Venkatesan, T. G. Srinivasan and P. R. Vasudeva Rao, Sep. Sci. Technol., 2013, 48, 2576-2581.

54 C. Xie, T. Toops, M. Lance, J. Qu, M. Viola, S. Lewis, D. Leonard and E. Hagaman, Catalysts, 2016, 6, 54.

55 X. Sun, H. Luo and S. Dai, Dalton Trans., 2013, 42, 82708275.

56 D. L. Minnick, R. A. Flores, M. R. Destefano and A. M. Scurto, J. Phys. Chem. B, 2016, 120, 7906-7919.

57 A. Rout, K. A. Venkatesan, T. G. Srinivasan and P. R. Vasudeva Rao, Sep. Purif. Technol., 2012, 95, 26-31.

58 X. Sun, C. L. Do-Thanh, H. Luo and S. Dai, Chem. Eng. J., 2014, 239, 392-398.

59 X. Sun, H. Luo and S. Dai, Talanta, 2012, 90, 132-137.

60 H. F. Eicke and H. Christen, J. Colloid Interface Sci., 1974, 46, 417-427.

61 H. F. Eicke and H. Christen, J. Colloid Interface Sci., 1974, 48, 281-290.

62 A. Faure, A. M. Tistchenko, T. Zemb and C. Chachaty, J. Phys. Chem., 1985, 89, 3373-3378.

63 A. Faure, T. Ahlnas, A. M. Tistchenko and C. Chachaty, J. Phys. Chem., 1987, 91, 1827-1834.

64 Z. Yu, N. Zhou and R. D. Neuman, Langmuir, 1992, 8, 18851888.

65 Z.-J. Yu and R. D. Neuman, Langmuir, 1995, 11, 1081-1086. 66 Z.-J. Yu and R. D. Neuman, Langmuir, 1994, 10, 2553-2558.

67 K. Feng and Z. A. Schelly, J. Phys. Chem., 1995, 99, 1721217218.

68 K. Feng and Z. A. Schelly, J. Phys. Chem., 1995, 99, 1721217218.

69 S. S. Quintana, R. D. Falcone, J. J. Silber, F. Moyano and N. M. Correa, Phys. Chem. Chem. Phys., 2015, 17, 7002-7011.

70 Q. Li, S. Weng, J. Wu and N. Zhou, J. Phys. Chem. B, 1998, 102, 3168-3174.

71 Q. Li, T. Li and J. Wu, J. Phys. Chem. B, 2000, 104, 90119016.

72 D. C. Steytler, T. R. Jenta, B. H. Robinson, J. Eastoe and R. K. Heenan, Langmuir, 1996, 12, 1483-1489.

73 F. M. Agazzi, R. D. Falcone, J. J. Silber and N. M. Correa, J. Phys. Chem. B, 2011, 115, 12076-12084.

74 A. M. Durantini, R. D. Falcone, J. J. Silber and N. M. Correa, J. Phys. Chem. B, 2013, 117, 3818-3828.

75 C. C. Villa, J. J. Silber, N. M. Correa and R. D. Falcone, ChemPhysChem, 2014, 15, 3097-3109.

76 R. D. Falcone, J. J. Silber and N. M. Correa, Phys. Chem. Chem. Phys., 2009, 11, 11096-11100.

77 A. M. Durantini, R. D. Falcone, J. J. Silber and N. M. Correa, J. Phys. Chem. B, 2013, 117, 3818-3828.

78 F. M. Agazzi, N. M. Correa and J. Rodriguez, Langmuir, 2014, 30, 9643-9653.
79 J. S. Florez Tabares, N. M. Correa, J. J. Silber, L. E. Sereno and P. G. Molina, Soft Matter, 2015, 11, 2952-2962.

80 T. Liu, Y. Xie and B. Chu, Langmuir, 2000, 16, 9015-9022.

81 A. Salabat, J. Eastoe, K. J. Mutch and R. F. Tabor, J. Colloid Interface Sci., 2008, 318, 244-251.

82 M. A. Crosio, N. M. Correa, J. J. Silber and R. D. Falcone, Org. Biomol. Chem., 2016, 3170-3177.

83 R. D. Falcone, N. M. Correa and J. J. Silber, Langmuir, 2009, 25, 10426-10429.

84 N. Zhou, Q. Li, J. Wu, J. Chen and S. Weng, Langmuir, 2001, 17, 4505-4509.

85 A. Maitra, J. Phys. Chem., 1984, 88, 5122-5125.

86 D. F. Evans and B. W. Ninham, J. Phys. Chem., 1986, 90, 226234.

87 Q. Li, T. Li and J. Wu, J. Colloid Interface Sci., 2001, 239, 522527.

88 F. M. Agazzi, J. Rodriguez, R. D. Falcone, J. J. Silber and N. M. Correa, Langmuir, 2013, 29, 3556-3566.

89 A. K. Ganguli, A. Ganguly and S. Vaidya, Chem. Soc. Rev., 2010, 39, 474-485.

90 V. E. Cuenca, R. D. Falcone, J. J. Silber and N. M. Correa, J. Phys. Chem. B, 2016, 120, 467-476.

91 C. M. O. Lépori, N. M. Correa, J. J. Silber and R. D. Falcone, Soft Matter, 2016, 12, 830-844.

92 C. A. Gracia, S. Gómez-Barreiro, A. González-Pérez, J. Nimo and J. R. Rodríguez, J. Colloid Interface Sci., 2004, 276, 408413.

93 C. P. Butts, J. Eastoe, D. J. Fermin, I. Grillo, H. Lee, D. Parker, D. Plana and R. M. Richardson, Langmuir, 2012, 28, 2502-2509.

94 S. Mandal, J. Kuchlyan, S. Ghosh, C. Banerjee, N. Kundu, D. Banik and N. Sarkar, J. Phys. Chem. B, 2014, 118, 59135923.

95 P. Brown, C. P. Butts, J. Eastoe, I. Grillo, C. James and A. Khan, J. Colloid Interface Sci., 2013, 395, 185-189.

96 A. Safavi, N. Maleki and F. Farjami, Colloids Surf., A, 2010, 355, 61-66.

97 B. S. Pattni, V. V Chupin and V. P. Torchilin, Chem. Rev., 2015, 115, 10938-10966.

98 N. Cheng, X. Ma, X. Sheng, T. Wang, R. Wang, J. Jiao and L. Yu, Colloids Surf., A, 2014, 453, 53-61.

99 M. Ramanathan, L. K. Shrestha, T. Mori, Q. Ji, J. P. Hill and K. Ariga, Phys. Chem. Chem. Phys., 2013, 15, 10580-10611.

100 S. Murgia, G. Palazzo, M. Mamusa, S. Lampis and M. Monduzzi, Phys. Chem. Chem. Phys., 2011, 13, 92389245.

101 T. L. Greaves, A. Weerawardena, C. Fong and C. J. Drummond, Langmuir, 2007, 23, 402-404. 